\title{
Involvment of Endogenous Prostaglandin in Emodin-Evoked Rat Colonic Anion Secretion
}

\author{
Jing-Dong XU, ${ }^{a}$ Wen WANG, ${ }^{b}$ Li-Sheng LI, ${ }^{a}$ Xin Chen, ${ }^{a}$ and Jin-Xia Zhu*, \\ ${ }^{a}$ Department of Physiology, Basic Medical College, Capital Medical University; and ${ }^{b}$ Institute of Pharmacology, Xuanwu \\ Hospital, Capital Medical University; Beijing 100069, China. Received May 14, 2007; accepted August 13, 2007
}

\begin{abstract}
It has been reported that emodin is able to promote gastrointestinal motility and stimulate large intestinal water secretion; however, the mechanism is still not clear. The aim of the present study is to examine the effects of emodin on the rat colonic transepithelial ion transport and the underlying mechanism. The study was carried out by means of the short circuit current $\left(I_{\mathrm{SC}}\right)$ recording. Basolateral application of emodin induced a concentration-dependent $I_{\mathrm{SC}}$ increase, and the $\mathrm{EC}_{50}$ was $76.0 \mu \mathrm{mol} / \mathrm{l}$. Pretreatment with epithelial $\mathrm{Na}^{+}$channel blocker, amiloride $(10 \mu \mathrm{mol} / \mathrm{l})$, did not affect the $I_{\mathrm{SC}}$ responses elicited by emodin, but removal of extracellular $\mathrm{Cl}^{-}$or apical pretreatment with $\mathrm{Cl}^{-}$channel blocker, glibenclamide $(1 \mathrm{mmol} / \mathrm{l})$ inhibited emodin-elicited $I_{\mathrm{SC}}$ responses by $76.3 \%$ and $83.8 \%$ respectively. Inhibiting basolateral $\mathrm{Na}^{+}-\mathrm{K}^{+}-2 \mathrm{Cl}^{-}$cotransporter (NKCC) with bumetanide $(100 \mu \mathrm{mol} / \mathrm{l})$ decreased emodin-induced $I_{\mathrm{SC}}$ from $118.1 \pm 6.7 \mu \mathrm{A} / \mathrm{cm}^{2}$ to $16.7 \pm 2.0 \mu \mathrm{A} / \mathrm{cm}^{2}$, which was reduced by 85.9\%. Basolateral pretreatment with neuronal $\mathrm{Na}^{+}$channel blocker tetrodotoxin (TTX) (1 $\left.\mu \mathrm{mol} / \mathrm{l}\right)$ did not affect emodin-induced $I_{\mathrm{SC}}$ increase, but pretreatment with indomethacin $(10 \mu \mathrm{mol} / \mathrm{l})$ alone or with both $\mathrm{TTX}$ and indomethacin significantly decreased emodin-induced $I_{\mathrm{SC}}$ increase by 88.4 and $81.2 \%$, respectively. The present study demonstrated that emodin was able to stimulate rat colonic epithelial $\mathrm{Cl}^{-}$secretion, which was predominantly mediated by endogenous prostaglandin release.
\end{abstract}

Key words emodin; colon; ion secretion; short-circuit current

The mammalian colon is the final station of the gastrointestinal (GI) tract, where the organism has the last opportunity to modify the electrolyte contents in the feces with balanced absorptive and secretory activities. Colonic epithelium, a typical electrolyte-transporting epithelium, lines the surface of both crypts and villi, and plays an important role in the maintenance of water and electrolyte balance.

Anthraquinones are present in the roots, bark or leaves of numerous plants such as senna, cascara, aloe, frangula and rhubarb. ${ }^{1}$ 1,3,8-Trihydroxy-6-methylanthraquinone (rhubarbemodin; emodin, for shortened form), an anthraquinone derivative from rhubarb (Rheum tanguticum MAXIM. ex. BALF.), plays an important role in brain protection against disturbances induced by severe cerebral injury, ${ }^{2,3)}$ antiviral activity against enveloped viruses ${ }^{4)}$ and GI motility. ${ }^{5}$ ) Emodin has been reported to be able to trigger acetylcholine release and cause muscle contraction by binding with muscarinic receptors. ${ }^{67)}$ The cellular signaling mechanism underlying emodin action has been reported to increase introcellular $\left[\mathrm{Ca}^{2+}\right]$ of gastrointestinal smooth muscle cells, ${ }^{8,9)}$ inhibition of the activation of $\mathrm{p} 38$ MAPK pathway and downregulation of the expression of fibronectin of renal dysfunction in diabetic nephropathy rats, ${ }^{10)}$ and vasorelaxant effect due to cGMP accumulation. ${ }^{7)}$ Aloe-emodin-9-anthrone (AE-anthrone), produced from barbaloin, caused not only an increase in the intestinal water content but also mucus secretion in the colon at its $1 / 2$ dose. ${ }^{11)}$ Further, synergistic purgative effect of aloeemodin anthrone and rhein anthrone in mice was resulted from synergistic stimulation of large intestinal transit and large intestinal water secretion, ${ }^{12}$ emodin, as an anthraquinone derivative from rhubarb, was demonstrated to tend to enhance the purgative activity in mice. ${ }^{13)}$ However, the effect of the emodin on anion secretion and its underling mechanism has not been illuminated.

Fluid secretion plays a key role in intestinal physiology. Under normal conditions, the intestine carries out the absorp- tion of luminal fluid, electrolytes and nutrients. A small amount of basal secretion facilitates hydration of the intestinal mucosa and mixing of intestinal contents. Fluid secretion is driven by active $\mathrm{Cl}^{-}$transport from the basolateral to the apical side of enterocytes.

Secretagogue-induced $\mathrm{GI} \mathrm{Cl}^{-}$secretion is important for the lubrication of intestinal contents during regular bowl movements or the flushing of microbial organisms or artificial irritants in host defense responses ${ }^{14)}$; epithelial $\mathrm{Cl}^{-}$channels, especially the cAMP-activated $\mathrm{Cl}^{-}$channels, play an important role in regulating and maintaining the normal physiological functions of the GI tract. The abnormal regulation of $\mathrm{Cl}^{-}$channels may result in diarrhea or constipation. ${ }^{15)}$ Therefore $\mathrm{Cl}^{-}$channels are very likely to be the target for pharmacological intervention. Using rat colonic epithelium and the short-circuit current technique, we undertook the present study to examine whether emodin exerted any effect on $\mathrm{Cl}^{-}$secretion and to investigate the underlying cellular signaling mechanism.

\section{MATERIALS AND METHODS}

Emodin Extraction and Identification The root of Polygonum multiflorum Rhubarb was purchased from Beijing-tongrentang, Beijing, China, and authenticated by Dr. Wen Wang. The air-dried root material was powdered and extracted with $80 \%$ ethanol. The combined solution was concentrated to afford a residue. After dissolving the residue in water, the aqueous solution was extracted with $n$-butanol. The extract was concentrated and chromatographed on a silica gel column using petroleum ether, EtOAc $(10: 1-0: 10)$, to give nine fractions. Fraction 3 was re-chromatographed on a silica gel column using petroleum ether, EtOAc $(7: 1)$ as eluent to afford the product as yellow needles, which was identified by comparing its data with those of an authentic sample. Its purity, determined by HPLC method, was $98.1 \%$. 
a.

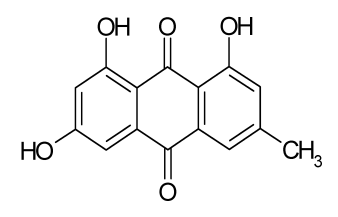

b.

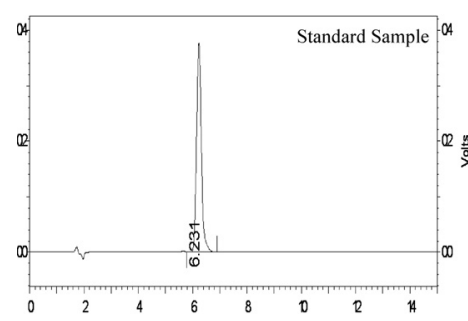

c.

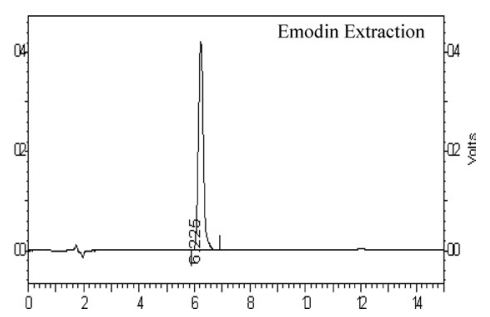

Fig. 1. (a) Structure of the Emodin, (b) Standard Sample by HPLC and (c) Purified Emodin by HPLC

HPLC conditions: An YMC C18 column, a mixture of methanol $0.1 \%$ phosphoric acid $(85: 15)$ as mobile phase, and UV detection at $254 \mathrm{~nm}$.

Materials Hank's balanced salt solution (HBSS), glibenclamide, amiloride hydrochloride, bumetanide, indomethacin, tetrodotoxin (TTX) were from Sigma (St. Louis, MO, U.S.A.). And stock solutions of some chemicals (glibenclamide, indomethacin, TTX, and bumatenide) were prepared in dimethylsulphoxide (DMSO). Final concentrations of DMSO never exceeded $0.1 \%(\mathrm{v} / \mathrm{v})$. Preliminary experiments indicated that the vehicle did not alter any baseline electrophysiological parameters.

Solutions Krebs-Henseit $(\mathrm{K}-\mathrm{H})$ solution had the following composition (mM): $\mathrm{NaCl}, 117 ; \mathrm{KCl}, 4.5 ; \mathrm{CaCl}_{2}, 2.5$; $\mathrm{MgCl}_{2}, 1.2 ; \mathrm{NaHCO}_{3}, 24.8 ; \mathrm{KH}_{2} \mathrm{PO}_{4}, 1.2 ;$ glucose, 11.1. In $\mathrm{Cl}^{-}$-free solution, $\mathrm{NaCl}, \mathrm{KCl}$ and $\mathrm{CaCl}_{2}$ were replaced by sodium gluconate, potassium gluconate and calcium gluconate, respectively. The solution was gassed with $95 \%$ $\mathrm{O}_{2}-5 \% \mathrm{CO}_{2}, \mathrm{pH} 7.4$, and temperature at $37^{\circ} \mathrm{C}$.

Tissue Preparation Animal protocols followed guidelines established by the NIH and were approved by Animal Care and Use Committee, Capital Medical University. Adult male Sprague-Dawley rats (Laboratory Animal Services Center, Capital Medical University) ranging in weight from 200 to $300 \mathrm{~g}$ had free access to standard rodent laboratory food and water until the day of the experiments. The animals were killed by cervical dislocation. The distal colon was removed and defined as the $c a .7 \mathrm{~cm}$ long segment proximal to the lymph node (typically situated $3 \mathrm{~cm}$ apart from the anus). Then the distal colon was divided into 4 segments, which were cut along the mesenteric border into a flat sheet and flushed with ice-cold Krebs-Henseit solution (K-HS). The tissue was pinned flat with the mucosal side down in a Sylgard-lined petri dish containing ice-cold oxygenated solution. The serosa, submucosa, and muscular layer were stripped away with fine forceps to obtain a mucosa preparation.

Short-Circuit Current Measurement The short-circuit current was measured in vitro in Ussing chambers. Flat sheet of colonic mucosa preparations were mounted between two halves of modified Ussing chambers, in which the total cross-sectional area was $0.5 \mathrm{~cm}^{2}$. The mucosal and serosal surfaces of tissue were bathed with $5 \mathrm{ml} \mathrm{K}-\mathrm{HS}$ by recirculation from a reservoir maintained at $37^{\circ} \mathrm{C}$ during the experiments. The $\mathrm{K}-\mathrm{HS}$ was bubbled with $95 \% \mathrm{O}_{2}$ and $5 \% \mathrm{CO}_{2}$ to maintain the $\mathrm{pH}$ of the solution at 7.4. Drugs could be added directly to the apical or basolateral side of epithelium. Responses were continuously recorded by computer. Transepithelial potential difference for every colonic mucosa was measured by the $\mathrm{Ag} / \mathrm{AgCl}$ reference electrodes (Physiologic Instruments, P2020S) connected to a preamplifier that was in turn connected to a voltage-clamp amplifier VCC MC6 (Physiologic Instruments). The change in $I_{\mathrm{SC}}$ was calculated on the basis of the value before and after simulation and was normalized as current per unit area of epithelial $\left(\mu \mathrm{A} \cdot \mathrm{cm}^{-2}\right)$, which allowed the curve area for $15 \mathrm{~min}$ to be calculated $(\mu \mathrm{A} \cdot \min )$. The change in current in response to the applied potential was used to calculate the transepithelial resistance of the monolayer by Ohm's Law. Experiments were normally repeated in different batches of colon mucosa to ensure that the data were reproducible.

Statistics The results were given as arithmetic means standard error of the mean (S.E.M.); " $n$ " refers to the number of rats. $\mathrm{EC}_{50}$ was calculated using the GraphPad Prism software 4.0 package. Statistical analyses were performed by Student's paired or unpaired $t$-test. " $p$ " values less than 0.05 were assumed to denote a significant difference.

\section{RESULTS}

Structure of emodin was shown in Fig. 1a and its purity, determined by HPLC, was $98.1 \%$ (Fig. 1c) compared with a standard sample (Fig. 1b).

Emodin-Induced $\boldsymbol{I}_{\mathrm{SC}}$ Responses in Different Concentrations After an equilibration time of $30 \mathrm{~min}$, emodin was added to the apical (mucosal) side or serosal (basolateral) side to investigate its effect on the transepithelial ion transport $\left(I_{\mathrm{SC}}\right)$ in freshly isolated rat colonic mucosa. The results indicated that addition of emodin into the mucosal side produced $I_{\mathrm{SC}}$ increase was much smaller than that of application of it into the basolateral side at the same higher dose (100 $\mu \mathrm{mol} / \mathrm{l})$ (Fig. 2a), suggesting that the effect of emodin on the colonic ion transport might be first acted on the serosal side but not luminal side. The following results therefore came from basolateral addition of emodin. The basolateral emodin induced $I_{\mathrm{SC}}$ response was concentration-dependent (Fig. 2b). When the dose of emodin was 1.0, 10, 100, 500 and $1000 \mu \mathrm{mol} / 1$, the $I_{\mathrm{SC}}$ increase evoked by emodin was $17.8 \pm 3.7 \mu \mathrm{A} / \mathrm{cm}^{2}(n=4), 52.5 \pm 3.5 \mu \mathrm{A} / \mathrm{cm}^{2} \quad(n=7), 124.9 \pm$ $12.0 \mu \mathrm{A} / \mathrm{cm}^{2} \quad(n=10), \quad 169.0 \pm 21.4 \mu \mathrm{A} / \mathrm{cm}^{2} \quad(n=12) \quad$ and $251.8 \pm 36.2 \mu \mathrm{A} / \mathrm{cm}^{2}(n=9)$, respectively, and the total charge transferred for $15 \mathrm{~min}$ was $132.2 \pm 64.4 \mu \mathrm{A} \cdot \min (n=6)$, $597.9 \pm 86.3 \mu \mathrm{A} \cdot \min (n=7), 1233.7 \pm 68.7 \mu \mathrm{A} \cdot \min (n=4)$, $1522.0 \pm 101.0 \mu \mathrm{A} \cdot \min (n=4)$ and $1734.7 \pm 101.2 \mu \mathrm{A} \cdot \min$ $(n=6)$, respectively, with an apparent $\mathrm{EC}_{50}$ of about $76.0 \mu \mathrm{mol} / 1$ (Fig. 2c). The transepithelial resistance wasn't significantly affected when the concentration of emodin was lower $(1,10,100 \mu \mathrm{mol} / \mathrm{l})$, but when the dose of emodin was 
a.

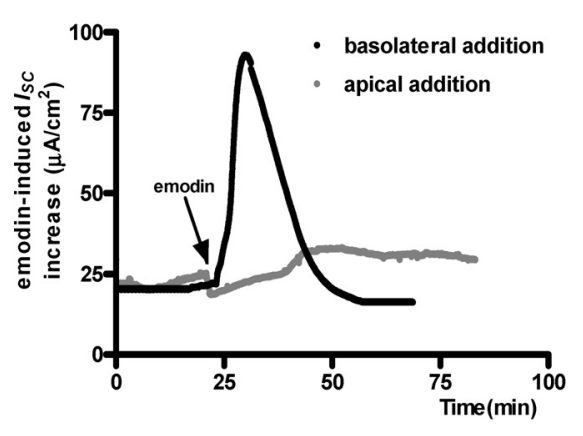

b.

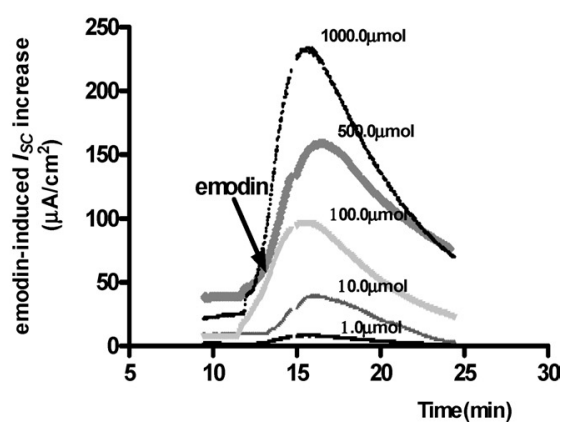

c.

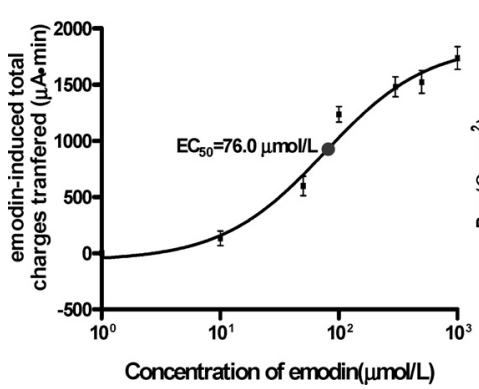

d.

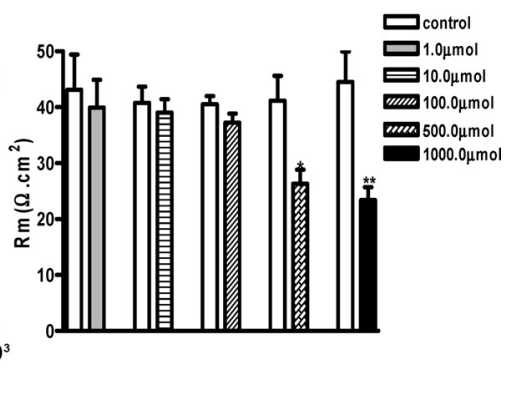

Fig. 2. Concentration-Response Curve for Emodin-Induced $I_{\mathrm{SC}}$ Response

(a) The $I_{\mathrm{SC}}$ responses evoked by luminal and basolateral addition of emodin $(100 \mu \mathrm{mol} / \mathrm{l})$. (b) Representative $I_{\mathrm{SC}}$ recordings in response $\left(\mu \mathrm{A} / \mathrm{cm}^{2}\right)$ to basolateral addition of emodin $(1,10,100,500,1000 \mu \mathrm{mol} / 1)$. Arrowheads indicate the time of emodin addition. (c) The concentration-response curve for emodin-induced total charge transferred in $15 \mathrm{~min}(\mu \mathrm{A} \cdot \mathrm{min})$. Each data point was obtained from at least 4 individual experiments. (d) The effect of different concentration of emodin on the transepithelial resistance. Higher dosage of emodin $(500,1000 \mu \mathrm{mol} / 1)$ significantly reduced colonic transepithelial resistance. Values are means \pm S.E.M.; $* p<0.05$, $* * p<0.01$.
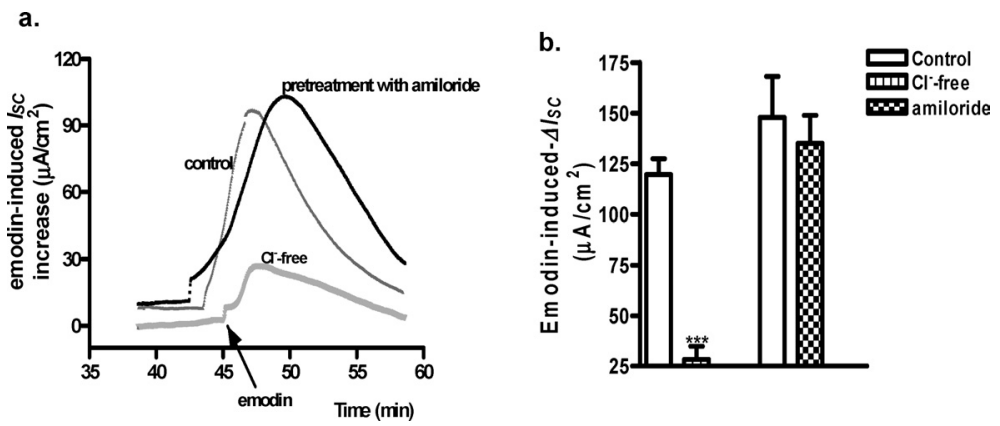

Fig. 3. Effect of $\mathrm{Cl}^{-}$Replacement and Transporter Inhibitors on the Emodin-Induced $I_{\mathrm{SC}}$ Response

(a) Representative $I_{\mathrm{SC}}$ recording with arrows indicating the response to emodin $(100 \mu \mathrm{mol})$ in normal and $\mathrm{Cl}^{-}$-free $\mathrm{K}-\mathrm{H}$ solutions; as well as in the pretreatment with $\mathrm{Na}^{+}$channel blocker, amiloride $(10 \mu \mathrm{mol} / \mathrm{l})$. (b) Summary of the effects of removal of extracellular $\mathrm{Cl}^{-}$and apical addition of amiloride (10 $\mu$ mol/l) on the basolateral application of emodininduced $I_{\mathrm{SC}}$ response. Values are mean \pm S.E.M.; $* * * p<0.001$.

heightened to $500 \mu \mathrm{mol} / \mathrm{l}$ and $1.0 \mathrm{mmol} / \mathrm{l}$, the resistance was significantly reduced to $26.3 \pm 2.5 \Omega \cdot \mathrm{cm}^{2}$ from $41.2 \pm 4.4$ $(n=6, p<0.05)$, and to $23.4 \pm 2.3 \Omega \cdot \mathrm{cm}^{2}$ from $44.5 \pm 5.4$ $(n=6, p<0.01)$ (Fig. 2d), respectively.

Anion Dependence of Emodin-Induced $\boldsymbol{I}_{\mathrm{SC}}$ In order to study the ion species involved in mediating the emodin-induced $I_{\mathrm{SC}}, \mathrm{Cl}^{-}$was removed from the bathing solution. The emodin $(100 \mu \mathrm{mol} / 1)$-induced response was significantly decreased by $\mathrm{Cl}^{-}$removal (Fig. 3a), from $119.5 \pm 7.9 \mu \mathrm{A} / \mathrm{cm}^{2}$ $(n=4)$ to $28.4 \pm 6.54 \mu \mathrm{A} / \mathrm{cm}^{2}$, about $76.3 \%$ reduction $(n=8$, $p<0.001$, Fig. 3b), indicating a $\mathrm{Cl}^{-}$dependence of the emodin-induced current. The effect of $\mathrm{Na}^{+}$channel blocker, amiloride, and $\mathrm{Cl}^{-}$channel blocker, glibenclamide, on the emodin-induced $I_{\mathrm{SC}}$ response was also examined. The apical addition of amiloride (10 $\mathrm{mm}$ ) was found to have no effect on emodin $(100 \mu \mathrm{mol} / 1)$-induced $I_{\mathrm{SC}}(n=6, p<0.05$, Fig. 3$)$. Apical-applied glibenclamide $(1 \mathrm{~mm})$ abolished the emodininduced $I_{\mathrm{SC}}$ response by $83.8 \%$, from $150.8 \pm 14.6 \mu \mathrm{A} / \mathrm{cm}^{2}$ to $24.4 \pm 3.9 \mu \mathrm{A} / \mathrm{cm}^{2}(n=6, p<0.001)$. Bumetanide $(100 \mathrm{~mm})$, a strong inhibitor of the $\mathrm{Na}^{+}-\mathrm{K}^{+}-2 \mathrm{Cl}^{-}$cotransporter, added to the basolateral side, resulted in a more than $85.9 \%$ reduction, from $118.1 \pm 6.7 \mu \mathrm{A} / \mathrm{cm}^{2}$ to $16.7 \pm 2.0 \mu \mathrm{A} / \mathrm{cm}^{2} \quad(n=7, p<$ $0.001)$ in the $I_{\mathrm{SC}}$ induced by emodin $(100 \mu \mathrm{mol} / \mathrm{l})$ as compared to control (Figs. 4a, b).

Involvement of Prostaglandin-Dependent Pathway As shown in Fig. 5b, basolateral application of TTX $(1 \mu \mathrm{mol} / 1)$, a neuronal $\mathrm{Na}^{+}$channel blocker, had no effect on the emodin-induced increase in $I_{\mathrm{SC}}$, from $111.4 \pm 11.8 \mu \mathrm{A} / \mathrm{cm}^{2}$ to $121.5 \pm 6.2 \mu \mathrm{A} / \mathrm{cm}^{2} \quad(n=4, p>0.05)$. However, basolateral pretreatment with indomethacin $(10 \mu \mathrm{mol} / 1)$, a cyclo-oxyge- 
a.

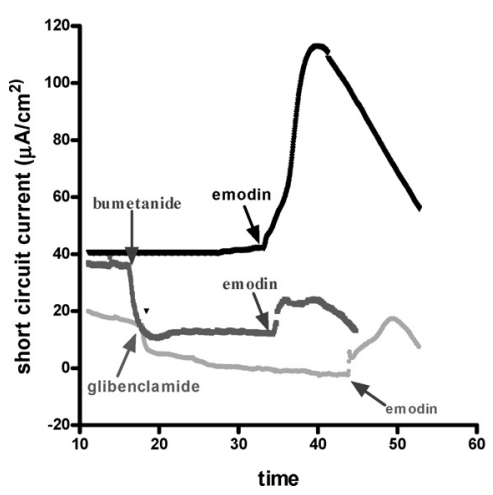

b.

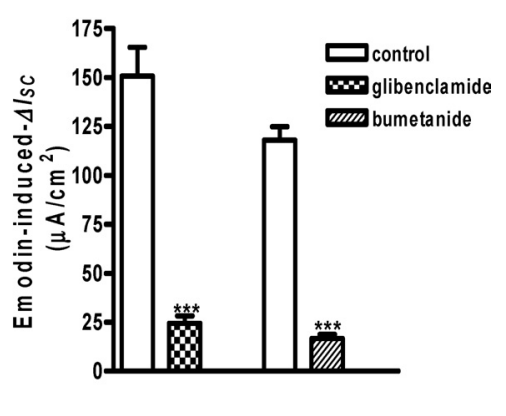

Fig. 4. Effect of CFTR Channel Inhibitors and $\mathrm{Na}^{+}-\mathrm{K}^{+}-2 \mathrm{Cl}^{-}$Cotransporter Inhibitors

(a) Representative $I_{\mathrm{SC}}$ recording with arrows indicating the time for the apical application of glibenclamide $(1 \mathrm{~mm} / \mathrm{l})$ or basolateral application of bumetanide (100 $\mu$ mol/l), respectively, and basolateral addition of emodin $(100 \mu \mathrm{mol} / \mathrm{l})$. (b) Summary of the effects of glibenclamide ( $1 \mathrm{mmol} / \mathrm{l}$, apical), bumetanide $(100 \mu$ mol/1, basolateral) on emodin-induced $\Delta I_{\text {SC. }}$ Values are means \pm S.E.M.; $* * * p<0.001$.

a.

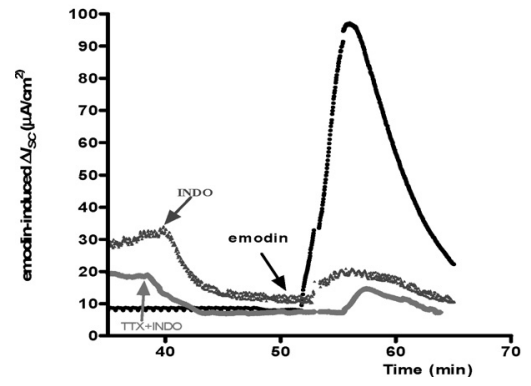

b.

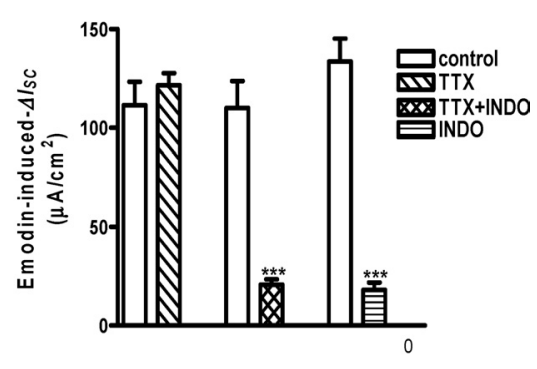

Fig. 5. Effect of a Cyclo-Oxygenase (COX) and Neuronal $\mathrm{Na}^{+}$Channel on the Emodin-Induce $\Delta I_{\mathrm{SC}}$

(a) Representative $I_{\mathrm{SC}}$ recording with arrows indicating the time for the basolateral application of indomethacin $(10 \mu \mathrm{mol} / 1)$, a cyclo-oxygenase $(\mathrm{COX})$ inhibitor, TTX ( $\left.1 \mu \mathrm{mol} / 1\right)$, a neuronal $\mathrm{Na}^{+}$channel blocker as well as emodin $(100 \mu \mathrm{mol} / \mathrm{l})$. (b) Summary of the effects of indomethacin, TTX (1 $\mu$ mol/l) alone, and both TTX and indomethacin. Values are means \pm S.E.M.; $* * * p<0.001$.

nase (COX) inhibitor, significantly decreased the emodin-induced $I_{\mathrm{SC}}$ response by more than $88.4 \%$ (Fig. 5a), from $155.2 \pm 19.7 \mu \mathrm{A} / \mathrm{cm}^{2} \quad(n=12)$ to $18.1 \pm 3.8 \mu \mathrm{A} / \mathrm{cm}^{2} \quad(n=6$, $p<0.001$, Fig. 5b) which was similar to that pretreatment with both TTX and indomethacin, emodin-induced $I_{\mathrm{SC}}$ response was reduced by $81.2 \%$ (Fig. 5a), from $110.1 \pm$ $13.6 \mu \mathrm{A} / \mathrm{cm}^{2}(n=10)$ to $20.7 \pm 2.8 \mu \mathrm{A} / \mathrm{cm}^{2} \quad(n=7, p<0.001$, Fig. 5b).

\section{DISCUSSION}

Pharmaceutical purgative preparations contained from Rheum palmatum have been widely used in China for hundreds of years to treat gastrointestinal disorders. ${ }^{16)}$ Emodin (1,3,8-trihydroxy-6-methylanthraquinone) is an anthraquinone derivative isolated from Rheum palmatum. ${ }^{17)}$ The reported biological effects of emodin include anti-tumor, antibacterial, and anti-inflammatory actions. ${ }^{18-20)}$ Apart from its beneficial effects on overall body functions, emodin has also been described in the improvement of digestion and gastrointestinal (GI) function. ${ }^{5)}$ It is reported that emodin is able to enhance the purgative action by injected directly into the caecum. ${ }^{13)}$ The present study further demonstrated the stimulatory effect of emodin on the colonic epithelial $\mathrm{Cl}^{-}$secretion. Epithelial $\mathrm{Cl}^{-}$channels have been known to play an important role in regulating and maintaining the normal physiolog- ical functions of the GI tract. ${ }^{21)}$ In this epithelium, $\mathrm{Cl}^{-}$secretion is mediated by two steps, i.e., the accumulation of cytosolic $\mathrm{Cl}^{-}$by $\mathrm{Na}^{+}-\mathrm{K}^{+}-2 \mathrm{Cl}^{-}$cotransporters in the basolateral membrane and then the exit of $\mathrm{Cl}^{-}$through $\mathrm{Cl}^{-}$channels in the apical membrane. ${ }^{2,23)}$ The supporting evidence for the stimulatory effect of emodin on $\mathrm{Cl}^{-}$secretion includes (1) emodin-induced $I_{\mathrm{SC}}$ increase was insensitive to the $\mathrm{Na}^{+}$channel blocker; amiloride, but sensitive to $\mathrm{Cl}^{-}$channel blocker, glibenclamide, and removal of extrocellular $\mathrm{Cl}^{-}$; (2) the response was inhibited by the inhibitor of $\mathrm{Na}^{+}-\mathrm{K}^{+}-2 \mathrm{Cl}^{-}$cotransporters, bumetanide. Thus a stimulation of $\mathrm{Cl}^{-}$secretion by emodin is readily confirmed. Furthermore, since $\mathrm{Cl}^{-}$secretion requires both the basolateral accumulation of $\mathrm{Cl}^{-}$by $\mathrm{Na}^{+}-\mathrm{K}^{+}-2 \mathrm{Cl}^{-}$cotransporter and apical exit through $\mathrm{Cl}^{-}$ channels, at this point basolateral $\mathrm{Na}^{+}-\mathrm{K}^{+}-2 \mathrm{Cl}^{-}$cotransporter would be the primary target of emodin since apical, but not basolateral, addition of emodin couldn't evoke an evident $I_{\mathrm{SC}}$ increase. However, the current results did provide evidence for the activation of apical $\mathrm{Cl}^{-}$channels, since apical addition of emodin decreased membrane resistance. The present study has also suggested that emodin-induced $\mathrm{Cl}^{-}$secretion is mediated by endogenous prostaglandin, since pretreatment of the tissue with cyclo-oxygenase (COX) inhibitor, indomethacin $(10 \mu \mathrm{mol} / \mathrm{l})$ blocked emodin-induced $I_{\mathrm{SC}}$ increase by more than $88.4 \%$. Taken together, the present results have demonstrated that emodin has a stimulatory ef- 
fect on gastrointestinal $\mathrm{Cl}^{-}$secretion by predominantly activating basolateral $\mathrm{Na}^{+}-\mathrm{K}^{-}-2 \mathrm{Cl}^{-}$cotransporter and apical $\mathrm{Cl}^{-}$channels. The ability of emodin stimulating $\mathrm{Cl}^{-}$secretion may contribute to its beneficial effects on GI tract, such as smoothing bowl movement and enhancing fluid clearance during host defense response. Nevertheless, the current study has established a model for the quantitative measurement of emodin effect on the GI tract and for further screening of its possible underlying mechanism. The differential sensitivity of the emodin-induced current response to bumetanide, or glibenclamide, and the reduction of the current by COX inhibitor, indomethacin, raised the possibility that emodin may activate cAMP-dependent $\mathrm{Cl}^{-}$channel, CFTR (cystic fibrosis transmembrane conductance regulator). It would be worthwhile to further explore the therapeutic potential of emodin for the clinic gastrointestinal disorders.

Acknowledgements This work was supported by the National Natural Science Foundation of China (30570672), Scientific Research Common Program of Beijing Municipal Commission of Education (KM200610025001), Natural Science Foundation of Beijing Municipal Commission of Science and Technical (7062031) and Foundation Clinic Research Program of Capital Medical University (2006JL05).

\section{REFERENCES}

1) Liu R., Zhang J., Liang M., Zhang W., Yan S., Lin M., J. Pharm. Biomed. Anal., 43, 1007-1012 (2007).

2) Gu J., Zhang X., Fei Z., Wen A., Qin S., Yi S., Chen Y., Li X., Chin. Med. J., 113, 529-531 (2000).

3) Huang L. Y., Hu J. D., Chen X. J., Zhu L. F., Hu H. I., Zhonghua Xue Ye Xue Za Zhi, 26, 348-351 (2005).
4) Sydiskis R. J., Owen D. G., Lohr J. L., Rosler K. H., Blomster R. N., Antimicrob. Agents Chemother, 35, 2463-2466 (1991).

5) Ma T., Qi Q. H., Xu J., Dong Z. L., Yang W. X., World J. Gastroenterol., 10, 1476-1479 (2004).

6) Ali S., Watson M. S., Osborne R. H., Auton. Autacoid. Pharmacol., 24, 103-105 (2004).

7) Huang H. C., Lee C. R., Chao P. D., Chen C. C., Chu S. H., Eur. J. Pharmacol., 205, 289-294 (1991).

8) Zhang H. L., Tang Z. Y., Yang J. X., Zhang Y., Li Y., Lin Y., FEBS Lett., 580, 469-473 (2006).

9) Zheyu C., Qinghui Q. I., Lixin L., Tao M., Xu J., Zhang L., Lunan Y., J. Surg. Res., 131, 80-85 (2006).

10) Wang J., Huang H., Liu P., Tang F., Qin J., Huang W., Chen F., Guo F., Liu W., Yang B., Eur. J. Pharmacol., 553, 297-303 (2006).

11) Yagi T., Yamauchi K., Kuwano S., J. Pharm. Pharmacol., 49, 22-25 (1997).

12) Ishii Y., Tanizawa H., Takino Y., Biol. Pharm. Bull., 17, 651-653 (1994).

13) Yagi T., Yamauchi K., J. Pharm. Pharmacol., 51, 93-95 (1999).

14) Greger R., Аnпu. Rev. Physiol., 62, 467-491 (2000).

15) Kobayashi S., Ikeda K., Suzuki M., Yamada T., Miyata K., Jpn. J. Pharmacol., 86, 281-288 (2001).

16) Wang C. C., Huang Y. J., Chen L. G., Lee L. T., Yang L. L., Planta Med., 68, 869-874 (2002).

17) Yim H., Lee Y. H., Lee C. H., Lee S. K., Planta Med., 65, 9-13 (1999).

18) Schorkhuber M., Richter M., Dutter A., Sontag G., Marian B., Eur. J. Cancer, 34, 1091-1098 (1998).

19) Lee H. Z., Wu C. H., Chang S. P., Int. J. Cancer, 113, 971-976 (2005).

20) Ernst F., Hetzel S., Stracke S., Czock D., Vargas G., Lutz M. P., Keller F., Jehle P. M., Eur. J. Clin. Invest., 31, 1029-1039 (2001).

21) Clarke L. L., Harline M. C., Am. J. Physiol., 274, G718-G726 (1998).

22) Loffing J., Moyer B. D., Reynolds D., Shmukler B. E., Alper S. L., Stanton B. A., Am. J. Physiol. Cell. Physiol., 279, C1016-C1023 (2000).

23) Brzuszczak I. M., Zhao J., Bell C., Stiel D., Fielding I., Percy J., Smith R., O’Loughlin E. V., J. Gastroenterol. Hepatol., 11, 804-810 (1996). 